\title{
Risk Factors for Changing Test Classification in the Danish Surveillance Program for Salmonella in Dairy Herds
}

\author{
L. R. Nielsen, ${ }^{* 1}$ L. D. Warnick, $\dagger$ and M. Greiner $\ddagger^{2}$ \\ *Department of Large Animal Sciences, Faculty of Life Sciences, University of Copenhagen, Groennegaardsvej 8, \\ DK-1870 Frederiksberg C, Denmark \\ †Department of Population Medicine and Diagnostic Sciences, College of Veterinary Medicine, Cornell University, Ithaca, NY \\ łInternational EpiLab, National Veterinary Institute, Danish Technical University, Copenhagen, Denmark
}

\begin{abstract}
A surveillance program in which all cattle herds in Denmark are classified into Salmonella infection categories has been in place since 2002. Dairy herds were considered test negative and thus most likely free of infection if Salmonella antibody measurements were consistently low in bulk tank milk samples collected every 3 mo. Herds were considered test positive and thus most likely infected if the 4-quarter moving average bulk tank milk antibody concentration was high or if there was a large increase in the most recent measurement compared with the average value from the previous 3 samples. The objective of this study was to evaluate risk factors for changing from test negative to positive, which was indicative of herds becoming infected from one quarter of the year to the next, and risk factors for changing from test positive to negative, which was indicative of herds recovering from infection between 2 consecutive quarters of the year. The Salmonella serotypes in question were Salmonella Dublin or other serotypes that cross-react with the Salmonella Dublin antigen in the ELISA (e.g., some Salmonella Typhimurium types). Two logistic regression models that accounted for repeated measurements at the herd level and controlled for herd size and regional effects were used. Data from 2003 was used for the analyses. A change from test negative to positive occurred in $2.0 \%$ of the quarterly observations $(n=21,007)$ from test negative dairy herds. A change from test positive to negative occurred in $10.0 \%$ of quarterly observations $(\mathrm{n}=6,168)$ available from test positive dairy herds. The higher the number of test-positive neighbor herds in the previous year-quarter, the more likely herds were to become test positive for Salmonella. The number of purchased cattle
\end{abstract}

\footnotetext{
Received May 24, 2006.

Accepted January 31, 2007.

${ }^{1}$ Corresponding author: lrn@life.ku.dk

${ }^{2}$ Current address: Federal Institute for Risk Assessment (BfR), Scientific Services, Unit 33-Epidemiology, Biostatistics and Mathematical Modelling, Berlin, Germany.
}

from test-positive herds was also associated with changing from test negative to positive. The bigger the herd, the more likely it was to change from negative to test positive. The effect of herd size on recovery was less clear. Large herds consisting mainly of large breeds or having test-positive neighbors in a 2 - $\mathrm{km}$ radius were less likely to change from test positive to negative, whereas the breed and neighbor factors were not found to be important for small herds. Organic production was associated with remaining test positive, but not with becoming test positive. The results emphasize the importance of external and internal biosecurity measures to control Salmonella infections.

Key words: risk factor, Salmonella, surveillance program dairy cattle

\section{INTRODUCTION}

Salmonella enterica ssp. enterica Dublin (S. Dublin) is host adapted to cattle and causes health and economic losses in the beef and dairy industries (Peters, 1985; Visser et al., 1997). Furthermore, it is a serious zoonosis, and though human cases are rare in Denmark (between 26 to 43 cases yearly in 2001 to 2004), they are often fatal (Helms et al., 2003; Anonymous, 2004, 2005). Salmonella Dublin is the most prevalent Salmonella serotype in cattle in Denmark, followed by $S$. Typhimurium. Therefore, it was decided to start a national surveillance program in Danish cattle with the primary goal of controlling $S$. Dublin. Data collection was started in 2001, and the program was launched in October 2002 by initiative of the Danish Veterinary and Food Administration and the Danish Cattle Federation.

In the surveillance program, all Danish cattle herds are classified into 3 infection categories. Dairy herds are classified based on bulk tank milk (BTM) samples that are tested using an ELISA based on an $S$. Dublin lipopolysaccharide antigen (O:9,12; Hoorfar et al., 1995). Other serotypes than $S$. Dublin may cross-react with this antigen because of $\mathrm{O}$-antigens on the bacterial surface that are common to those carried by $S$. Dublin 
[e.g., O:12 in S. Typhimurium (Konrad et al., 1994; Hoorfar et al., 1995)]. Thus, the term Salmonella in this study implies $S$. Dublin or other serotypes that occur in cattle and can cross-react with the antigen used in the ELISA in the surveillance program. In Denmark, most of these would be $S$. Typhimurium (Anonymous, 2004).

For dairy herds, a Salmonella category is determined from the 4 most recent ELISA results. Samples are collected approximately every $3 \mathrm{mo}$, but extra samples at other intervals may also be requested by farmers. There has to be at least $3 \mathrm{wk}$ and no more than 5 mo between each sample to be used for the Salmonella category determinations. The average proportion of background-corrected optical density value of the sample to a known positive control sample (ODC\%) is calculated from these 4 measurements.

Herds not producing milk are classified based on ELISA measurements on blood samples that are collected routinely for evaluation of the herd status of bovine virus diarrhea or voluntarily submitted for analysis from animals above 8 mo of age (Nielsen et al., 2003).

Category $(\mathbf{C}) 1$ is considered most likely free of Salmonella. If enough blood samples have been collected and all are below the cutoff of 50 ODC \%, herds not producing milk are classified C1. Dairy herds are classified C1 if the average ODC\% of the last $4 \mathrm{BTM}$ measurements is below 25 and no increase of more than 20 ODC\% is found when comparing the last measurement to the average of the 3 previous measurements. Until March 2006, C2 and C3 were divided into 2 sublevels. Sublevel C2a was considered likely to be infected because of antibody responses above the cutoff values. Sublevel $\mathrm{C} 2 \mathrm{~b}$ was not classifiable because of lack of data or because of contact to herds in $\mathrm{C} 2 \mathrm{a}$ or $\mathrm{C} 2 \mathrm{~b}$. Herds in C3a had clinical salmonellosis diagnosed by bacteriological culture (usually outbreak herds). Sublevel C3b had the bacteria detected by culture, but clinical salmonellosis had not been diagnosed or the herd had purchased cattle from a C3a or C3b herd. Laboratory results and classification categories are recorded in a database that is part of the Danish Cattle Database. The systematically collected data on Salmonella antibodies in all Danish dairy herds provides a unique opportunity to evaluate risk factors for the infection at herd level.

The use of BTM ELISA for herd classification of dairy herds was first suggested by Hoorfar et al. (1994) who recommended the use of this test for screening and certification programs. In a small study ( $\mathrm{n}=160$ BTM samples) it was found that there was a good association between herd history of salmonellosis, herd location, and clinical status of the herd and the BTM ELISA response (Hoorfar et al., 1995). In the Danish surveil- lance program, the BTM ELISA measurements of 4 samples are used for the classification, and the validity of the program testing scheme in dairy herds was evaluated on a large scale using a simulation model based on field study data from dairy herds known to be infected with $S$. Dublin and $S$. Typhimurium (Warnick et al., 2006). This study found good validity of the classification (sensitivity $=95 \%$, specificity $=96 \%$, negative predictive value $=99 \%$, and positive predictive value $=$ $80 \%$ ) at a national prevalence of $15 \%$ truly infected dairy herds. Infection was defined for that study as having at least one culture-positive fecal sample from cattle or a within-herd prevalence of at least $5 \%$ based on individual animal ELISA results.

Risk factors for Salmonella infection in cattle at the herd level can be evaluated from 2 perspectives: 1 ) the risk of introduction of the infection to a previously uninfected herd; and 2) the risk of currently being infected with Salmonella bacteria. The introduction has been shown to be influenced by management practices of the herd and location of the herd. Trade of living animals, grazing with cattle from other farms, and low level of biosecurity for professional visitors have been found as significant risk factors for introduction of infectious organisms to the herd (van Schaik et al., 2002). In a study of 1,429 Danish dairy herds, the risk of becoming infected with Salmonella (measured as a change from negative to positive BTM ELISA response) increased when nearby neighbors were infected. Also, the risk increased with the prevalence of seropositive herds in the region (Wedderkopp et al., 2001). Pastures recently contaminated with infected slurry are also an important risk for new infection (Taylor and Burrows, 1971; Taylor, 1973).

The aim of our study was to identify factors influencing the risk of dairy herds changing test status as a measure of Salmonella infection or recovery. Salmonella serotypes of primary interest were $S$. Dublin, $S$. Typhimurium or other serotypes that may cross-react with the $S$. Dublin-antigen used in the BTM ELISA testing scheme in the Danish surveillance program.

\section{MATERIALS AND METHODS}

\section{Data Sources}

Data sources included the Central Husbandry Register, the Danish Cattle Database, and data from the National Surveillance Program for $S$. Dublin. All live born cattle are ear tagged at birth, and these 3 databases are more or less integrated and contain recordings of birth, location, movement, clinical records, and laboratory results of all cattle in Denmark, thus providing data on herd size, breed, location, and trading patterns on all cattle herds. Geographical information 
on all farms was obtained from the Map and Land Register Authority in Denmark.

\section{National Surveillance Program Data}

For the objective of this study, we used the ELISA ODC\% results from the National Surveillance Program database to recalculate Salmonella test results for all dairy herds. The test program validity and the relationship between BTM ELISA measurements and individual cow antibodies were described elsewhere (Nielsen and Ersbøll, 2005; Warnick et al., 2006). In another study, it was shown that mainly serogroup B-serotypes such as $S$. Typhimurium may cross-react with a $S$. Dublin antigen because of common lipopolysaccharide Oantigens 1 and 12 on the cell surface (Konrad et al., 1994). The herds were test negative if the 4-BTM moving average was $\mathrm{ODC} \%<25$, and no increase of $>20$ ODC\% was found when comparing the most recent measurement to the average of the 3 previous measurements. Test-positive dairy herds included those with BTM ELISA results that exceeded either of the ELISA test cut-off criteria described above. Thus, all dairy herds were denoted either test positive or test negative for each sampling date. The actual regulatory categories used in the surveillance program $(\mathrm{C} 1, \mathrm{C} 2 \mathrm{a}, \mathrm{C} 2 \mathrm{~b}$, $\mathrm{C} 3 \mathrm{a}$, and $\mathrm{C} 3 \mathrm{~b}$ ) were not used to define the response variables for these analyses, but $\mathrm{C} 1$ would be similar to test negative and C2a to test positive. Very few dairy herds were assigned C2b, C3a, and C3b in the surveillance program, and these herds were grouped according to their antibodies into test negative or positive.

For the analyses, all herds had a Salmonella test result assigned to each year-quarter (YQ) based on the last 4 consecutive BTM samples. If a herd was classified more than once during the same $\mathrm{YQ}$, because more than one BTM were collected, the test result for that YQ was selected randomly. The full data set contained 70,871 data lines from 8,694 dairy herds from the period October 2001 to March 2004, and the herds had their Salmonella test result determined for between 1 and $11 \mathrm{YQ}$ with a median of 9 and Q1 to Q3 of 8 to 10. Potential risk factors were constructed as either time dependent with measurements on a quarterly basis or as a onetime recording representing the entire sampling period. For several of the variables, however, data were only available for a limited period as described in Data Editing and Descriptive Statistics.

Herds not producing milk were grouped based on blood samples collected in the herds or at slaughter. The surveillance program in herds not producing milk had changed several times in the period 2002-2004 and was most likely of varying accuracy compared with the program for dairy herds. Therefore, data from these herds were only used to construct variables concerning characteristics of neighbor. They were not included as study herds as such. Overall, the apparent prevalence of Salmonella infection in cattle herds not producing milk was around $1.5 \%$.

\section{Study Herds}

All dairy herds were included in the study regardless of whether they ceased operations during the period from which data were extracted (2001 to 2004). The BTM measurements were available starting in 2001 when data collection was initiated. Dairy herds were defined as herds that had weekly SCC measured from BTM as part of a compulsory milk quality control program because this definition gives the most updated information on which herds were truly milk-producing herds. Out of the 8,694 dairy herds with adequate samples, 1,007 (11.6\%) were defined as Jersey herds and 7,682 (88.4\%) were defined as large breed herds (Holstein Friesian, Red Danish Cattle, and mixed breeds; 5 herds had missing values for breed). The distinction between Jersey and large breeds was based on the geometric average percentage of fat in milk from weekly recordings in the Danish Cattle Database.

\section{Data Editing and Descriptive Statistics}

The following variables were extracted and constructed from the databases and used in the risk factor analyses. Even though some data (e.g., the Salmonella data) were available for the full period from 2001 to 2004, the final data sets used for the risk factor study had to be restricted to the 4 quarters of 2003 because of lack of data outside this period for most of the risk factors.

Year-Quarter. The YQ were based on the months January to March, April to June, July to September, and October to December for each year 2001 to 2004 . The distribution of test-positive herds and test-negative herds for each YQ in the study period is shown in Table 1 .

Region. Geographical regions were constructed by dividing Denmark into 6 regions so that each of the 6 had approximately the same number of dairy herds, and the area within the same region was geographically contiguous (except for separation by bodies of water) and had approximately the same apparent prevalence. To meet the latter criterion, North Jutland was further divided into 2 regions because of the large difference in apparent prevalence between the northern and southern part. The resulting 7 regions and apparent prevalence of each region in June 2003 are illustrated in Figure 1. 
Table 1. Distribution of antibody test-positive and test-negative dairy herds in each quarter of the year in the study period 2001 to 2004 in the surveillance program for Salmonella in Denmark

\begin{tabular}{lccc}
\hline $\begin{array}{l}\text { Year and } \\
\text { quarter }\end{array}$ & $\begin{array}{c}\text { Number of } \\
\text { test-positive } \\
\text { dairy herds }\end{array}$ & $\begin{array}{c}\text { Number of } \\
\text { test-negative } \\
\text { dairy herds }\end{array}$ & $\begin{array}{c}\text { Overall } \\
\text { apparent } \\
\text { prevalence, \% }\end{array}$ \\
\hline 2001, fourth & 2,016 & 5,644 & 26.3 \\
2002, first & 1,962 & 6,456 & 23.3 \\
2002, second & 1,813 & 6,173 & 22.7 \\
2002, third & 1,841 & 5,954 & 23.6 \\
2002, fourth & 1,752 & 5,661 & 23.6 \\
2003, first & 1,684 & 5,895 & 22.2 \\
2003, second & 1,574 & 5,714 & 21.6 \\
2003, third & 1,449 & 5,116 & 22.1 \\
2003, fourth & 1,555 & 5,630 & 21.6 \\
\hline
\end{tabular}

${ }^{1}$ Data from the first, second, and third quarters of 2001 and first quarter of 2004 are not shown here because data were incomplete.

Season. Season was defined as winter (January to March), spring (April to June), summer (July to September), and fall (October to December).

Organic. Eight percent of the 8,694 dairy herds were recorded as organic in 2003. Information about which herds were organic was obtained from the Danish Plant Directorate and merged with data from the Danish Cattle Database. Although organic status was coded as a time-dependent variable, for practical purposes it can be considered as nonvarying because virtually all herds $(>99 \%)$ were classified as organic or not organic for the entire study period.

Neighbors in 2-km Radius. The number of neighbors included beef and dairy herds in a $2-\mathrm{km}$ radius around each study herd. This number was calculated for all of 2003, so that if a herd were recorded active at any point in time during 2003 it would be counted as a neighbor and would be assigned neighbors as well. The number was used to represent the full study period because it was assumed not to change over time.

C2a or C3a Neighbors. The number of cattle herds (beef and dairy) classified C2a or C3a in the surveillance program in a $2-\mathrm{km}$ radius around each dairy herd in the previous YQ. Data were available from first YQ of 2003 to first YQ of 2004.

Close-Contact Neighbors. The legally required area used to spread manure from each dairy and beef herd according to the regulations was calculated, and the radii were calculated for circles equivalent to this area centered around each herd. The area depended mainly on the herd size and breed. This variable showed how many neighboring dairy and beef herd circles in which each dairy herd was located during the previous
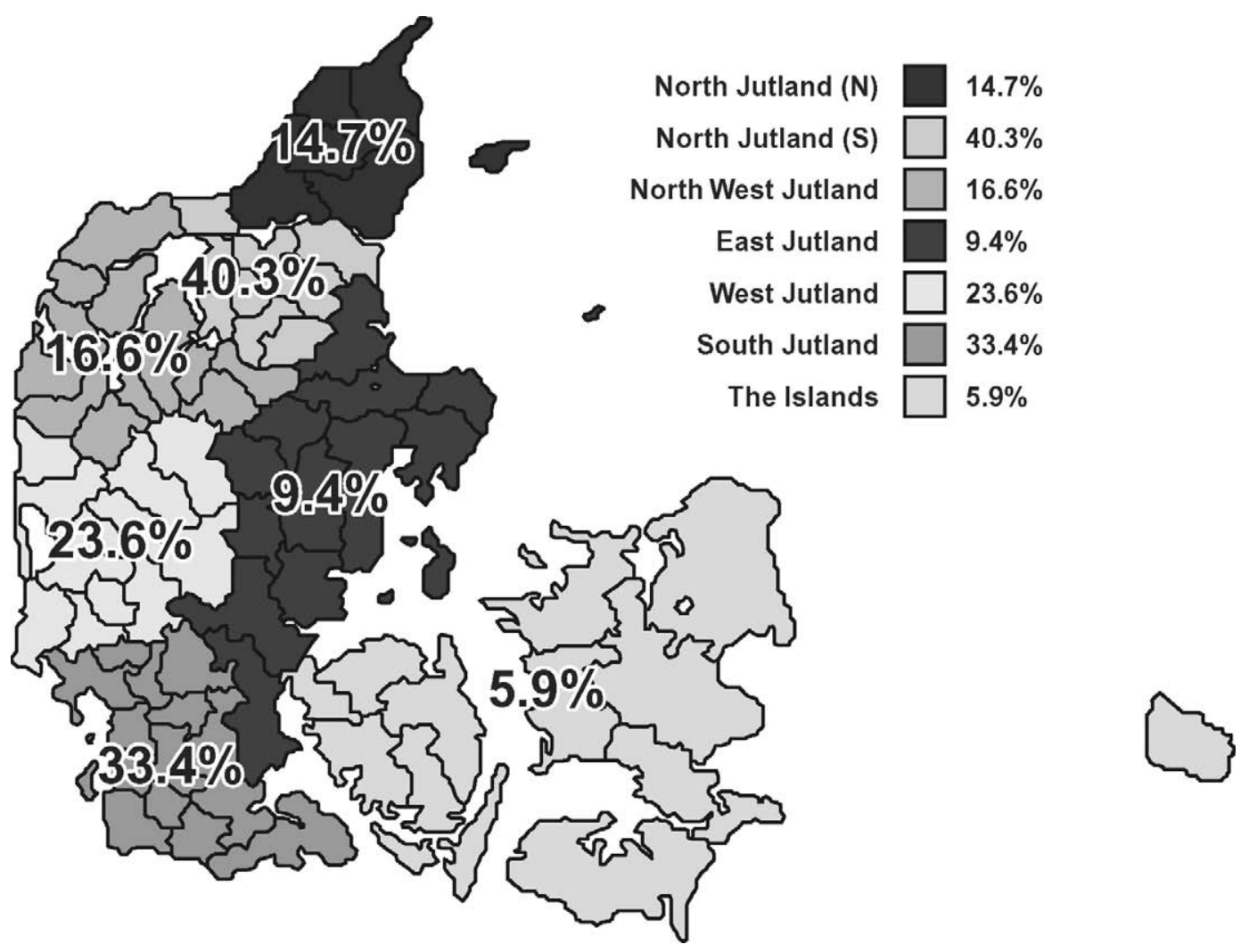

Figure 1. The 7 regions of Denmark and apparent Salmonella prevalence of each region in June 2003. 
YQ. Data were available from first YQ of 2003 to first YQ of 2004.

C2a or C3a Close-Contact Neighbor. Similar to the previous variable, except this variable only counted the number of circles from herds that were classified in $\mathrm{C} 2 \mathrm{a}$ or C3a in the surveillance program in the previous YQ.

Individual animal numbers, dates of birth, dates of entry to the holding, identification of the farm of origin, animal date, and reason for departure (e.g., breeding, slaughter, export, or death) were extracted from the Danish Cattle Database. These data were used to construct the following variables:

Calf Mortality. Calf mortality in the previous YQ was calculated as the proportion of live-born calves that were ear-tagged and died within 1 to $90 \mathrm{~d}$ after birth. Data were available from fourth YQ of 2002 to third YQ of 2003.

Source Herds. Total number of dairy and beef source herds for cattle purchased in the previous YQ. Data were available from second YQ of 2002 to first $\mathrm{YQ}$ of 2004.

Test-Positive Source Herds. Total number of testpositive dairy source herds for cattle purchased in the previous YQ. Data were available from second YQ of 2002 to first YQ of 2004 .

Purchased Cattle. Total number of dairy and beef cattle purchased in the previous YQ. Data were available from second YQ of 2002 to first YQ of 2004.

Purchased Cattle from Test-Positive Herds. Number of cattle purchased from test-positive dairy herds in the previous YQ. Data were available from second YQ of 2002 to first YQ of 2004.

Herd Size. Total number of cattle (regardless of age and production type) on the premises counted per month and averaged for each YQ. Data were available from second YQ of 2001 to fourth YQ of 2003.

\section{Statistical Method of Analysis}

Two separate multivariable logistic regression models were used to analyze risk factors associated with a change of status between $2 \mathrm{YQ}$ from test negative to positive and from test positive to negative, respectively. The factors analyzed in the model related to the YQ just before the change in test status (e.g., herd size, purchase of cattle, number of infected neighbors) or they could be factors that were considered fixed over the full study period (e.g., number of neighbor cattle herds in a $2-\mathrm{km}$ radius). Continuous variables were checked visually for a linear relationship with the log odds of the response variable before inclusion in the model. Because all variables other than herd size did not show linear relationships, it was decided to categorize these (see Table 2 for details on the categories).

The variables were assessed for colinearity with the conclusion that total number of purchased cattle and number of source herds in the previous YQ could not be included in the models simultaneously. Neither could the number of purchased cattle from test-positive herds and number of test-positive source herds, number of neighbor circles and total number of neighbors in a $2-\mathrm{km}$ radius, number of $\mathrm{C} 2 \mathrm{a}$ or $\mathrm{C} 3 \mathrm{a}$ close-contact neighbors and number of $\mathrm{C} 2 \mathrm{a}$ or $\mathrm{C} 3 \mathrm{a}$ neighbors in a $2-\mathrm{km}$ radius. The variables that were left out initially because of colinearity were checked in the final model by replacing the analogous correlated variables.

The models were constructed as multivariable logistic regression models controlling for the correlation of repeated measurements from the same herd by using generalized estimating equations (GEE). All main effects were included in the initial model together with all interactions with herd size. Backward selection was used to remove nonsignificant interaction terms and nonsignificant main effects in that order. Then 2-way interaction terms of the significant main effects were tested in the model. Significance level criteria for variables and interaction terms to remain in the final model were $P<0.05$. For the variable selection all variables remained in the class statement to analyze on the same data set. After the final model with significant effects was determined, the model was tested on a data set including all data available for the class variables remaining in the model. This data set contained data from 4 YQ (first to fourth YQ of 2003). This restricted data set was a result of lack of data for several risk factors as illustrated in the section on Data Editing and Descriptive Statistics.

Odds ratios with $95 \%$ confidence limits were calculated as described by Hosmer and Lemeshow (2000). For the calculation of odds ratios for herd size and variables with significant interactions with herd size in the test-positive to test-negative model, 3 examples were selected for illustration (100, 200, and 300 cattle). It was necessary to choose specific numbers for the herd size as examples to illustrate the difference between combinations of risk factors because herd size was a continuous variable in the models. In Denmark, a total herd size of 100 would be considered a small dairy herd, 200 a medium-sized dairy herd, and 300 a large dairy herd.

\section{Software}

The SAS version 8.2 program was used for data editing and statistical analyses. The GENMOD procedure was used for logistic regression models with a repeated 
Table 2. Descriptive statistics of categorical risk factors and changes in test results ${ }^{1}$

\begin{tabular}{|c|c|c|c|c|}
\hline \multirow[b]{2}{*}{ Variable and level } & \multicolumn{2}{|c|}{ Previously test-negative herds } & \multicolumn{2}{|c|}{ Previously test-positive herds } \\
\hline & $\mathrm{n}$ & $\begin{array}{l}\% \text { test negative } \\
\text { to positive }\end{array}$ & $\mathrm{n}$ & $\begin{array}{l}\% \text { test positive } \\
\text { to negative }\end{array}$ \\
\hline 0 to 5 & 5,379 & 2.3 & 1,098 & 15.7 \\
\hline 6 to 10 & 15,790 & 2.4 & 4,549 & 11.7 \\
\hline 11 to 15 & 16,553 & 2.6 & 5,418 & 10.9 \\
\hline$>15$ & 8,421 & 3.4 & 2,947 & 11.7 \\
\hline 0 & 13,729 & 1.3 & 2,382 & 12.8 \\
\hline 1 & 5,214 & 2.2 & 1,608 & 11.3 \\
\hline 2 & 2,149 & 2.7 & 1,032 & 9.4 \\
\hline$>2$ & 1,996 & 4.1 & 1,694 & 7.7 \\
\hline \multicolumn{5}{|c|}{ Calf mortality in previous year-quarter (proportion) } \\
\hline 0 & 12,502 & 2.1 & 2,875 & 13.4 \\
\hline 0 to 0.05 & 2,041 & 2.7 & 843 & 8.4 \\
\hline 11 to 20 & 1,548 & 4.6 & 638 & 10.7 \\
\hline$>20$ & 1,113 & 5.5 & 674 & 9.2 \\
\hline \multicolumn{5}{|c|}{$\begin{array}{l}\text { Number of cattle purchased from test-positive } \\
\text { dairy herds in previous year-quarter }\end{array}$} \\
\hline 0 & 39,798 & 2.5 & 10,957 & 11.6 \\
\hline 1 to 10 & 823 & 8.0 & 811 & 9.4 \\
\hline 11 to 20 & 119 & 14.3 & 150 & 8.0 \\
\hline$>20$ & 72 & 18.0 & 147 & 6.8 \\
\hline \multicolumn{5}{|c|}{ Total number of source herds in previous year-quarter } \\
\hline 0 & 29,579 & 2.4 & 7,976 & 11.3 \\
\hline 1 & 7,313 & 2.8 & 2,380 & 11.9 \\
\hline$>1$ & 3,920 & 4.8 & 1,709 & 10.9 \\
\hline \multicolumn{5}{|c|}{ Total number of test-positive source dairy herds in previous year-quarter } \\
\hline 0 & 39,798 & 2.5 & 10,957 & 11.6 \\
\hline Large breed & 40,358 & 2.8 & 13,357 & 11.3 \\
\hline Jersey & 6,161 & 1.6 & 743 & 19.5 \\
\hline \multicolumn{5}{|l|}{ Organic } \\
\hline No & 43,091 & 2.6 & 12,337 & 12.2 \\
\hline Yes & 3,434 & 3.5 & 1,766 & 8.5 \\
\hline \multicolumn{5}{|l|}{ Season } \\
\hline Jan to Mar & 11,730 & 2.0 & 3,940 & 13.8 \\
\hline Apr to Jun & 11,550 & 1.7 & 3,583 & 10.6 \\
\hline Jul to Sep & 10,092 & 2.7 & 2,813 & 10.2 \\
\hline Oct to Dec & 13,153 & 4.0 & 3,767 & 11.8 \\
\hline \multicolumn{5}{|l|}{ Region } \\
\hline N. Jutland (N) & 3,611 & 1.9 & 873 & 15.8 \\
\hline N. Jutland (S) & 3,985 & 5.4 & 2,591 & 9.3 \\
\hline North West Jutland & 7,937 & 2.6 & 1,647 & 15.1 \\
\hline East Jutland & 7,585 & 1.3 & 4,533 & 9.7 \\
\hline West Jutland & 8,486 & 2.6 & 2,854 & 10.2 \\
\hline South Jutland & 7,888 & 4.2 & 1,011 & 17.0 \\
\hline The Islands & 7,033 & 1.3 & 594 & 20.7 \\
\hline
\end{tabular}

${ }^{1}$ Percentage of dairy herds changing from test negative to positive or from test positive to negative out of the total number of herds in each scenario (n) according to antibody measurement data from the national surveillance program for Salmonella in Denmark.

${ }^{2} \mathrm{C} 2 \mathrm{a}=$ Salmonella category in the national surveillance program based on high antibodies.

${ }^{3} \mathrm{C} 3 \mathrm{a}=$ Salmonella category in the national surveillance program based on bacteriological culture-confirmed salmonellosis due to Salmonella enterica subspecies enterica Dublin. 
statement and an unstructured working correlation structure to account for the intraherd correlation of response measurements within the same herd. The "within-subject option" was used to allow for adjustment of correlation in the case of missing values for certain YQ.

\section{RESULTS}

In the full data set of Salmonella test results, a change from test negative to positive occurred in $2.6 \%$ of the available quarterly observations $(\mathrm{n}=46,525)$ from testnegative dairy herds. A change from test positive to negative occurred in $11.7 \%$ of quarterly observations ( $\mathrm{n}=$ 14,103) available from test-positive dairy herds.

After the data set was reduced to including the relevant period with data for all important variables, the data set for test negative to positive changes had 21,007 observations, and changes occurred in $2 \%$ of these observations. The data set for test positive to negative changes had 6,168 observations, with changes occurring in $10 \%$ of these observations. Descriptive statistics including proportion of the 2 types of changes in herd status for each level of the categorical variables are given in Table 2 .

\section{Model 1: Change from Test Negative to Positive Indicating Introduction of Infection}

The parameter estimates and significance levels in the model for becoming test positive after being test negative, which is indicative of new infection, are given in Table 3. The higher the number of C2a or C3a neighbor herds was in the local area (2-km radius around the herd), the higher $(P=0.006)$ was the risk of changing from test negative to positive. The risk of changing was also higher $(P<0.0001)$ if a herd had purchased animals from test positive herds in the previous YQ than if it had only purchased animals from test-negative herds or not purchased animals at all. Because of high colinearity between number of purchased cattle and number of source herds, it was not possible to include both variables in the model simultaneously. When the number of testpositive source herds was tested in this model instead of number of purchased cattle from test-positive herds, this risk factor was also significant with increasing number of test-positive source herds leading to higher odds of changing from Salmonella test negative to positive (results not shown).

\section{Model 2: Change from Test Positive to Negative Indicating Recovery from Infection}

Parameter estimates and significance levels of risk factors from the final model for changing from test posi- tive to negative (indicative of recovery) are shown in Table 4. Odds ratios with $95 \%$ confidence limits for each main effect and examples from the interaction terms are shown in Table 5. The odds of changing from test positive to negative were influenced by the local cattle herd density (measured as number of neighbor herd manure disposal areas that included the herd at risk). Herds that did not have such close-contact neighbors in the previous YQ had higher odds of becoming test negative than herds with one or more close-contact neighbors. This variable was highly dependent on the size of the neighbor herds because large herds would require larger areas for manure disposal than small herds. One other factor that described local cattle herd density was present in the final model (i.e., in the interaction between herd size and number of $\mathrm{C} 2 \mathrm{a}$ or $\mathrm{C} 3 \mathrm{a}$ neighbors in a $2-\mathrm{km}$ radius). The calculation of the latter explanatory variable did not depend on the size of the neighboring herds. For medium and large herds, having 2 or more C2a or C3a herds in a 2-km radius lead to significantly smaller odds of becoming test negative in the current YQ after having been test positive in the previous YQ. For small herds there was no effect of having such neighbors.

Dairy herds that did not have organic production systems had significantly higher odds of recovering to test negative compared with organic herds. Breed seemed to have an effect in large herds. For small herds there was no difference between the odds of changing to test negative, but for large herds (e.g., 300 cattle) the odds of changing to test negative were smaller for large breeds than for Jersey.

\section{DISCUSSION}

\section{Herd Classification and Variables}

Salmonella Dublin was the most commonly isolated serotype in Danish cattle, and it is known to usually persist longer in the herds than other serotypes (Boqvist and Vagsholm, 2005). Whereas it is likely that $S$. Dublin accounted for most herd infections in the present study period, the interpretation of the results extends to other cross-reacting $S$. enterica ssp. enterica serotypes that spread in similar ways to $S$. Dublin.

The models for new infection and recovery of Salmonella infection in Danish cattle were based on herd test status determined by repeated bulk tank milk measurements. Thus, the outcome of interest was measured indirectly. There are no perfect diagnostic methods available to measure whether a herd is truly infected with Salmonella (Veling et al., 2002). With the method used in our study, the herd-positive predictive value in the program was not perfect (estimated to 80\%), and this might have had an impact on the results (Warnick et al., 2006). Whereas Veling et al. (2002) found the sensitivity of 
Table 3. Risk factors associated with a change in classification from test negative to positive (indicative of new infection) in the Danish surveillance program for Salmonella in dairy herds in 2003

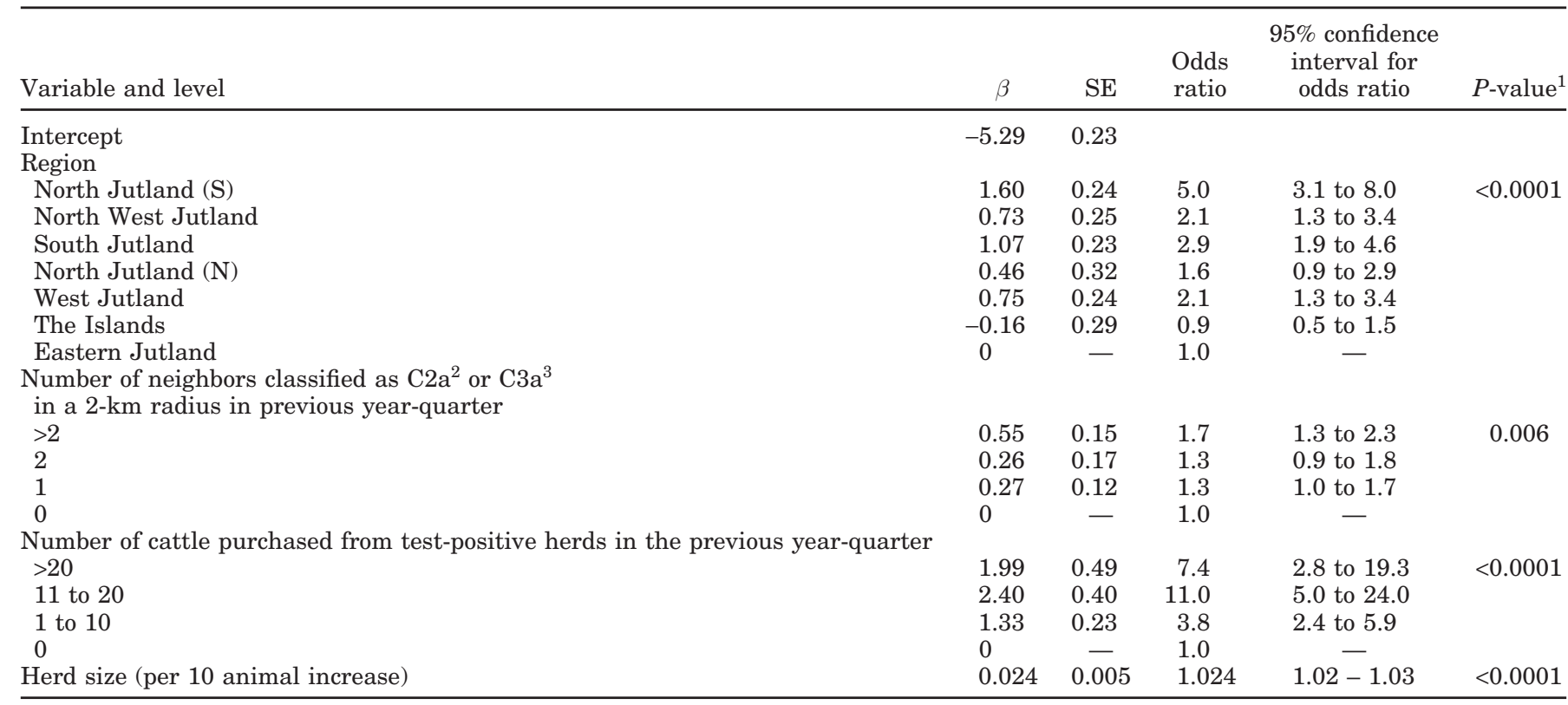

${ }^{1} P$-value estimated by the score statistics for type 3 contrasts in the generalized estimating equation analysis.

${ }^{2} \mathrm{C} 2 \mathrm{a}=$ Salmonella category in the national surveillance program based on high antibodies.

${ }^{3} \mathrm{C} 3 \mathrm{a}=$ Salmonella category in the national surveillance program based on bacteriological culture-confirmed salmonellosis due to Salmonella enterica subspecies enterica Dublin.

BTM ELISA to be small (54\%) when basing herd classification on one single BTM sample, combining the results from 4 repeated samples as is done in the Danish Salmonella surveillance program seemed to improve the sensitivity (95\%; Warnick et al., 2006). Although detailed information on herds used for evaluation of the BTM ELISA (Nielsen and Ersbøll, 2005) raises confidence that risk factors identified in the study presented here are applicable to changes in herd infection status, potential effects of misclassification should be considered. For instance, a herd may become test positive after a rise in antibodies in the BTM when purchasing animals with antibodies from another herd without necessarily having introduced the infection into the herd. This would be more likely to occur if the source herd was test positive. If this phenomenon was common in a large number of herds, the effect of purchase on becoming infected could have been overestimated in our analysis. Other studies, however, support the finding that the risk of becoming infected increases with purchase from other herds, and biologically it makes sense that this risk is mainly increased if the source herd is infected and thus test positive (Vaessen et al., 1998; van Schaik et al., 2002). Based on clinical experience with the BTM ELISA test as well as bacteriological culture results and other observations of test program herds, we believe the analysis identified factors likely to be associated with changes in Salmo- nella infection status of the herd and not just with changes in herd test results. Consistency with published results from other field studies strengthens this conclusion for the effect of purchasing cattle from infected herds and a number of other risk factors identified.

One possible improvement of the models could be to include infection history from YQ earlier than the most recent YQ. If a test-negative herd had been infected with Salmonella (or had been test positive) within the last couple of years it was probably more likely to change to test positive again after reinfection from persistently infected animals or surviving bacteria in the environment (Wray et al., 1989; House et al., 1993). This should preferably be assessed using a data set containing data from a longer period than was available for this study. Another variable that could not be included in this study was the concurrent infection with other diseases, such as metabolic diseases, liver fluke infestation, or viral infections that may reduce the resistance to Salmonella in the herds (Aitken et al., 1981; Vaessen et al., 1998).

\section{Model Results}

The number of presumably infected (C2a or C3a) neighbor herds was a significant risk factor common for both models. The higher this number, the more likely change from test negative to positive was to occur and 
Table 4. Final model parameter estimates, SE, and $P$-values for risk factors associated with a change from test positive to test negative (indicative of recovery) in the Danish surveillance program for Salmonella in dairy herds in 2003

\begin{tabular}{|c|c|c|c|}
\hline Variable and level & $\beta$ & $\mathrm{SE}$ & $P$-value ${ }^{1}$ \\
\hline Intercept & -2.49 & 0.39 & \\
\hline \multicolumn{4}{|l|}{ Region } \\
\hline North Jutland (S) & -0.17 & 0.21 & \multirow[t]{7}{*}{0.003} \\
\hline North West Jutland & 0.21 & 0.21 & \\
\hline South Jutland & -0.31 & 0.20 & \\
\hline North Jutland (N) & 0.18 & 0.23 & \\
\hline West Jutland & -0.16 & 0.20 & \\
\hline The Islands & 0.40 & 0.25 & \\
\hline Eastern Jutland & 0 & 0 & \\
\hline \multicolumn{4}{|c|}{ Close-contact neighbors in the previous year-quarter } \\
\hline Yes & 0.31 & 0.11 & \multirow[t]{2}{*}{0.006} \\
\hline No & 0 & 0 & \\
\hline \multicolumn{4}{|l|}{ Breed } \\
\hline Large breed & 0.39 & 0.32 & \multirow[t]{2}{*}{0.2} \\
\hline Jersey & 0 & 0 & \\
\hline \multicolumn{4}{|l|}{ Organic } \\
\hline No & 0.54 & 0.17 & \multirow[t]{2}{*}{0.0003} \\
\hline Yes & 0 & 0 & \\
\hline \multicolumn{4}{|c|}{$\begin{array}{l}\text { Number of neighbors classified as } C 2 \mathrm{a}^{2} \text { or } \mathrm{C} 3 \mathrm{a}^{3} \\
\text { in a } 2-\mathrm{km} \text { radius in previous year-quarter }\end{array}$} \\
\hline$>2$ & 0.14 & 0.26 & \multirow[t]{4}{*}{0.4} \\
\hline 2 & -0.12 & 0.33 & \\
\hline 1 & -0.33 & 0.23 & \\
\hline 0 & 0 & 0 & \\
\hline Herd size (per 10 heads) & 0.014 & 0.014 & 0.2 \\
\hline \multicolumn{4}{|l|}{ Herd size $\times$ breed } \\
\hline Large breed & -0.004 & 0.001 & \multirow[t]{2}{*}{0.02} \\
\hline Jersey & 0 & & \\
\hline \multicolumn{4}{|c|}{$\begin{array}{l}\text { Herd size } \times \text { number of neighbors classified as } \mathrm{C}^{2} \mathrm{a}^{2} \text { or } \mathrm{C}^{3} \mathrm{a}^{3} \\
\text { in a } 2-\mathrm{km} \text { radius in previous year-quarter }\end{array}$} \\
\hline$>2$ herds & -0.003 & 0.001 & \multirow[t]{4}{*}{0.03} \\
\hline 2 herds & -0.001 & 0.002 & \\
\hline 1 herd & 0.001 & 0.001 & \\
\hline 0 herds & 0 & 0 & \\
\hline
\end{tabular}

${ }^{1} P$-value estimated by the score statistics for type 3 contrasts in the generalized estimating equation analysis.

${ }^{2} \mathrm{C} 2 \mathrm{a}=$ Salmonella category in the national surveillance program based on high antibodies.

${ }^{3} \mathrm{C} 3 \mathrm{a}=$ Salmonella category in the national surveillance program based on bacteriological culture-confirmed salmonellosis due to Salmonella enterica subspecies enterica Dublin.

the less likely test-positive herds were to become test negative between 2 YQ. The results are supported by another study (Wedderkopp et al., 2001). In that study it was found that the risk for a dairy herd to change infection status was associated with the BTM status of the nearest neighbors and the prevalence of seropositive herds in the geographic area.

Herd size was also included in both models. The bigger the herd, the more likely it was to change from test negative to positive (model 1). Changing from test positive to negative, the effect of herd size was less clear. Large herds consisting of large breed or having C2a or C3a neighbors in a 2-km radius were less likely to recover, whereas the breed and neighbor factors were not found to be important for small herds. Herd size is often found to be a risk factor for infectious diseases (Vaessen et al., 1998; Warnick et al., 2001). Herd size, however, may be an indirect measure of management. In this study, we did not have access to data to investigate possible underlying reasons for the effect of herd size. In 2 studies in which there were more elaborate details of management available for the model, no association between Salmonella fecal shedding and herd size was detected (Fossler et al., 2005a,b).

The number of purchased cattle from test-positive herds was associated with becoming infected. Other studies have found purchase of live animals a significant risk factor for introduction of Salmonella infection to the herd (Wray et al., 1990, 1991; Vaessen et al., 1998; van Schaik et al., 2002). In the surveillance program, purchase of cattle from $\mathrm{C} 2 \mathrm{a}$ dairy herds led to automatic classification in $\mathrm{C} 2 \mathrm{~b}$ for 3 mo from the day of purchase. This was a restriction implemented to attempt to minimize transmission between herds. The $\mathrm{C} 2 \mathrm{~b}$ was an indicator that the herd had been involved in high-risk activity (contact to assumed infected herds), and other herds 
Table 5. Odds ratios (OR) and 95\% confidence intervals (CI) of the OR for risk factors for a change from test positive to negative (indicative of recovery) in the Danish surveillance program for Salmonella in dairy herds in 2003

\begin{tabular}{|c|c|c|c|}
\hline Variable and level & & OR & $95 \%$ CI of OR \\
\hline \multicolumn{4}{|l|}{ Region } \\
\hline North Jutland (S) & & 0.9 & 0.6 to 1.3 \\
\hline North West Jutland & & 1.2 & 0.8 to 1.9 \\
\hline South Jutland & & 0.7 & 0.5 to 1.1 \\
\hline North Jutland (N) & & 1.2 & 0.8 to 1.9 \\
\hline West Jutland & & 0.9 & 0.6 to 1.3 \\
\hline The Islands & & 1.5 & 0.9 to 2.4 \\
\hline Eastern Jutland & & 1.0 & - \\
\hline \multicolumn{4}{|c|}{$\begin{array}{l}\text { Close-contact neighbors in the } \\
\text { previous year-quarter }\end{array}$} \\
\hline Yes & & 1.4 & 1.1 to 1.7 \\
\hline No & & 1 & - \\
\hline \multicolumn{4}{|l|}{ Organic } \\
\hline No & & 1.7 & 1.2 to 2.4 \\
\hline Yes & & 1 & - \\
\hline Herd size & Breed & & \\
\hline \multirow[t]{2}{*}{100} & Large & 1.0 & 0.6 to 1.6 \\
\hline & Jersey & 1.0 & - \\
\hline \multirow[t]{2}{*}{200} & Large & 0.7 & 0.5 to 1.0 \\
\hline & Jersey & 1.0 & - \\
\hline \multirow[t]{2}{*}{300} & Large & 0.5 & 0.3 to 0.8 \\
\hline & Jersey & 1.0 & - \\
\hline Herd size & $\begin{array}{l}\text { Number of neighbors classified as } \mathrm{C} 2 \mathrm{a}^{1} \\
\text { or } \mathrm{C} 3 \mathrm{a}^{2} \text { in a } 2-\mathrm{km} \text { radius in previous } \\
\text { year-quarter }\end{array}$ & & \\
\hline \multirow[t]{4}{*}{100} & $>2$ herds & 0.9 & 0.6 to 1.2 \\
\hline & 2 herds & 0.8 & 0.6 to 1.2 \\
\hline & 1 herd & 0.8 & 0.6 to 1.1 \\
\hline & 0 herds & 1.0 & - \\
\hline \multirow[t]{4}{*}{200} & $>2$ herds & 0.6 & 0.5 to 0.9 \\
\hline & 2 herds & 0.7 & 0.6 to 1.0 \\
\hline & 1 herd & 1.0 & 0.8 to 1.2 \\
\hline & 0 herds & 1.0 & - \\
\hline \multirow[t]{4}{*}{300} & $>2$ herds & 0.5 & 0.3 to 0.8 \\
\hline & 2 herds & 0.7 & 0.5 to 1.0 \\
\hline & 1 herd & 1.1 & 0.8 to 1.5 \\
\hline & 0 herds & 1.0 & - \\
\hline
\end{tabular}

${ }^{1} \mathrm{C} 2 \mathrm{a}=$ Salmonella category in the national surveillance program based on high antibodies.

${ }^{2} \mathrm{C} 3 \mathrm{a}=$ Salmonella category in the national surveillance program based on bacteriological culture-confirmed salmonellosis due to Salmonella enterica subspecies enterica Dublin.

were less likely to purchase cattle from the herds in this category. The fact that purchase from test-positive herds was found to be a significant risk factor for changing to test positive supports this control strategy. Whether the length of the automatic classification period based on trade could be improved was not investigated further in this study.

Organic production was only associated with persistence of test-positive results, not with becoming test positive. This may be because of regulations about management procedures in organic herds that allow for easy spread of infection from dams or calving environment to newborn calves and calving cows such as the practice of leaving the calf with the dam up to 3 to $4 \mathrm{~d}$ after birth, less aggressive antibiotic use, no preventive treatments allowed, and possible differences in feeding strategies (Fossler et al., 2005a,b).
In the final model there was no association between calf mortality in the previous $\mathrm{YQ}$ and a change in test results. Data quality for the variable of calf mortality was, however, not ideal. The variable was constructed as the number of dead calves out of all calves born. The calf mortality percentage varied dramatically because of the small number of calves born per YQ in some herds. It is likely that increased calf mortality more often would follow rather than precede the change of Salmonella status. For future studies, it should be investigated how to construct a reliable calf mortality or calf morbidity variable and to consider how to include it in a model as it is likely to be associated with many outbreaks and reinfections with $S$. Dublin and other types of Salmonella in dairy herds, and it may be useful as an early indicator of new or reinfection with Salmonella. 


\section{CONCLUSIONS}

The results have implications for controlling Salmonella infection in cattle herds. Herd owners should be aware of the infection risk when purchasing new livestock from an infected herd and the risk of having infected neighbors. High external biosecurity is necessary in such herds. There is a need to inform organic farmers, herds in high cattle density areas, and herds with test positive neighbors how to control and eradicate Salmonella. High internal and external biosecurity is required, not just control of within-herd transmission that tends to be the main focus in infected herds. The results provided support for trade restrictions upon purchase of cattle from $\mathrm{C} 2 \mathrm{a}$ herds in the surveillance program because there was in fact a high risk of infection associated with this behavior.

The association between calf mortality (or calf morbidity) and Salmonella infection should be investigated using higher quality data than was available in this project. This would help determine if calf mortality, calf morbidity, or both are useful as an early warning of new infection in herds that have not yet had an increase in BTM ELISA.

\section{ACKNOWLEDGMENTS}

The project was performed at and funded by the International EpiLab (F04-0239), the Danish Directorate of Food, Fisheries and Agro Business (DFFE, J.nr. 340165-03-742), and the Danish Cattle Federation. The authors thank Mette Marie Andersen for preparing data for the study and Lasse Engbo Christiansen for work on constructing variables for analysis from register data.

\section{REFERENCES}

Aitken, M. M., P. W. Jones, G. A. Hall, D. L. Hughes, and G. T. Brown. 1981. Responses of fluke-infected and fluke-free cattle to experimental reinfection with Salmonella Dublin. Res. Vet. Sci. $31: 120-126$.

Anonymous. 2004. Pages 1-32 in Annual Report on Zoonoses in Denmark 2003. Ministry of Family and Consumer Affairs, Copenhagen, Denmark.

Anonymous. 2005. Pages 1-40 in Annual Report on Zoonoses in Denmark 2004. Ministry of Family and Consumer Affairs, Copenhagen, Denmark.

Boqvist, S., and I. Vagsholm. 2005. Risk factors for hazard of release from Salmonella-control restriction on Swedish cattle farms from 1993 to 2002. Prev. Vet. Med. 71:35-44.

Fossler, C. P., S. J. Wells, J. B. Kaneene, P. L. Ruegg, L. D. Warnick, J. B. Bender, L. E. Eberly, S. M. Godden, and L. W. Halbert. 2005a. Herd-level factors associated with isolation of Salmonella in a multi-state study of conventional and organic dairy farms: I. Salmonella shedding in cows. Prev. Vet. Med. 70:257-277.

Fossler, C. P., S. J. Wells, J. B. Kaneene, P. L. Ruegg, L. D. Warnick, J. B. Bender, L. E. Eberly, S. M. Godden, and L. W. Halbert. 2005b. Herd-level factors associated with isolation of Salmonella in a multi-state study of conventional and organic dairy farms: II. Salmonella shedding in calves. Prev. Vet. Med. 70:279-291.
Helms, M., P. Vastrup, P. Gerner-Smidt, and K. Mølbak. 2003. Short and long term mortality associated with foodborne bacterial gastrointestinal infections: Registry based study. Br. Med. J. 326:357361.

Hoorfar, J., N. C. Feld, A. L. Schirmer, V. Bitsch, and P. Lind. 1994. Serodiagnosis of Salmonella Dublin infection in Danish dairy herds using O-antigen based enzyme-linked immunosorbent assay. (Published erratum appears in Can. J. Vet. Res. 1995, 59:25). Can. J. Vet. Res. 58:268-274.

Hoorfar, J., P. Lind, and V. Bitsch. 1995. Evaluation of an O antigen enzyme-linked immunosorbent assay for screening of milk samples for Salmonella Dublin infection in dairy herds. Can. J. Vet. Res. 59:142-148.

Hosmer, D. W., and S. Lemeshow. 2000. Applied Logistic Regression, 2nd ed. John Wiley \& Sons Inc., New York, NY.

House, J. K., B. P. Smith, G. W. Dilling, and L. D. Roden. 1993. Enzymelinked immunosorbent assay for serologic detection of Salmonella Dublin carriers on a large dairy. Am. J. Vet. Res. 54:1391-1399.

Konrad, H., B. P. Smith, G. W. Dilling, and J. K. House. 1994. Production of Salmonella serogroup D (O9)-specific enzyme-linked immunosorbent assay antigen. Am. J. Vet. Res. 55:1647-1651.

Nielsen, L. R., A. K. Ersbøll. 2005. Factors associated with variation in bulk-tank-milk Salmonella Dublin ELISA ODC\% in dairy herds. Prev. Vet. Med. 68:165-179.

Nielsen, L. R., E. Rattenborg, and J. Nielsen. 2003. National surveillance program for Salmonella Dublin in Danish cattle. Abstract number 847 in Proc. 10th Symp. Int. Soc. Vet. Epidemiol. Economics 2003, Viña del Mar, Chile.

Peters, A. R. 1985. An estimation of the economic-impact of an outbreak of Salmonella-Dublin in a calf rearing unit. Vet. Rec. 117:667-668.

Taylor, R. J. 1973. A further assessment of the potential hazard for calves allowed to graze pasture contaminated with Salmonella Dublin in slurry. Br. Vet. J. 129:354-358.

Taylor, R. J., and M. R. Burrows. 1971. The survival of Escherichia coli and Salmonella Dublin in slurry on pasture and the infectivity of $S$. Dublin for grazing calves. Br. Vet. J. 127:536-542.

Vaessen, M. A., J. Veling, K. Frankena, E. A. Graat, and T. Klunder. 1998. Risk factors for Salmonella Dublin infection on dairy farms. Vet. Quart. 20:97-99.

van Schaik, G., Y. H. Schukken, M. Nielen, A. A. Dijkhuizen, H. W. Barkema, and G. Benedictus. 2002. Probability of and risk factors for introduction of infectious diseases into Dutch SPF dairy farms: A cohort study. Prev. Vet. Med. 54:279-289.

Veling, J., H. W. Barkema, J. van der Schans, F. van Zijderveld, and J. Verhoeff. 2002. Herd-level diagnosis for Salmonella enterica subsp. enterica serovar Dublin infection in bovine dairy herds. Prev. Vet. Med. 53:31-42.

Visser, S. C., J. Veling, A. A. Dijkhuizen, and R. B. M. Huirne. 1997. Economic losses due to Salmonella Dublin in dairy cattle. Pages 143-151 in Proc. Dutch/Danish Symp. Anim. Health Manage. Economics, Copenhagen, Denmark. A. R. Kristensen, ed. Royal Veterinary and Agricultural University, Frederiksberg, Denmark.

Warnick, L. D., L. M. Crofton, K. D. Pelzer, and M. J. Hawkins. 2001. Risk factors for clinical salmonellosis in Virginia, USA cattle herds. Prev. Vet. Med. 49:259-275.

Warnick, L. D., L. R. Nielsen, J. Nielsen, and M. Greiner. 2006. Simulation model estimates of test accuracy and predictive values for the Danish Salmonella surveillance program in dairy herds. Prev. Vet. Med. 77:284-303.

Wedderkopp, A., U. Stroger, and P. Lind. 2001. Salmonella dublin in Danish dairy herds: Frequency of change to positive serological status in bulk tank milk ELISA in relation to serostatus of neighbouring farms. Acta Vet. Scand. 42:295-301.

Wray, C., N. Todd, I. M. McLaren, and Y. E. Beedell. 1991. The epidemiology of Salmonella in calves: The role of markets and vehicles. Epidemiol. Infect. 107:521-525.

Wray, C., N. Todd, I. McLaren, Y. Beedell, and B. Rowe. 1990. The epidemiology of Salmonella infection of calves: The role of dealers. Epidemiol. Infect. 105:295-306.

Wray, C., Q. C. Wadsworth, D. W. Richards, and J. H. Morgan. 1989. A three-year study of Salmonella Dublin infection in a closed dairy herd. Vet. Rec. 124:532-535. 